February 2018

\title{
The Rhetorical Algorithm: WikiLeaks and the Elliptical Secrets of Donald J. Trump
}

Atilla Hallsby

North Carolina State University, hall1039@umn.edu

Follow this and additional works at: https://scholarworks.sjsu.edu/secrecyandsociety

Part of the Communication Technology and New Media Commons, Critical and Cultural Studies Commons, and the Speech and Rhetorical Studies Commons

\section{Recommended Citation}

Hallsby, Atilla. 2018. "The Rhetorical Algorithm: WikiLeaks and the Elliptical Secrets of Donald J. Trump." Secrecy and Society 1(2). https://doi.org/10.31979/

2377-6188.2018.010202 https://scholarworks.sjsu.edu/secrecyandsociety/vol1/iss2/2

This Article is brought to you for free and open access by the School of Information at SJSU ScholarWorks. It has been accepted for inclusion in Secrecy and Society by an authorized administrator of SJSU ScholarWorks. For more information, please contact scholarworks@sjsu.edu.

\section{(c) (1) $\odot$}

This work is licensed under a Creative Commons Attribution-No Derivative Works 4.0 License. 


\title{
The Rhetorical Algorithm: WikiLeaks and the Elliptical Secrets of Donald J. Trump
}

\author{
Abstract \\ Algorithms were a generative force behind many of the leaks and secrets that dominated \\ the 2016 election season. Taking the form of the identity-anonymizing Tor software that \\ protected the identity of leakers, mathematical protocols occupied a prominent place in the \\ secrets generated during the presidential campaign. This essay suggests that the rhetorical \\ trope of ellipsis offers an equally crucial, algorithmic formula for explaining the public \\ production of these secrets and leaks. It then describes the 2016 DNC leak and Donald \\ Trump's "I love Wikileaks" moment using the trope of ellipsis, which marks a discursive \\ omission or gap in official executive discourse.
}

\section{Keywords}

2016 U.S. election, algorithms, ellipsis, rhetoric, secrecy, secrecy studies, Donald J. Trump, WikiLeaks

\section{Cover Page Footnote}

Atilla Hallsby is a Lecturer at North Carolina State University. The author wishes to thank Dan Faltesek, Genghis Hallsby, Jeremy Grossman, J. Alexander McVey, Chris Ingraham, Emily Winderman, and Heather Woods for conversations and comments that guided the development of this essay. He would also like to thank Susan Maret for her editorship, as well as Chris Hables Gray and his anonymous reviewer for providing close guidance on the final version of this essay. 


\title{
The Rhetorical Algorithm: WikiLeaks and the Elliptical Secrets of Donald J. Trump
}

\begin{abstract}
Algorithms were a generative force behind many of the leaks and secrets that dominated the 2016 election season. Taking the form of the identityanonymizing Tor software that protected the identity of leakers, mathematical protocols occupied a prominent place in the secrets generated during the presidential campaign. This essay suggests that the rhetorical trope of ellipsis offers an equally crucial, algorithmic formula for explaining the public production of these secrets and leaks. It then describes the 2016 DNC leak and Donald Trump's "I love Wikileaks" moment using the trope of ellipsis, which marks a discursive omission or gap in official executive discourse.
\end{abstract}

Keywords: 2016 U.S. election, algorithms, ellipsis, rhetoric, secrecy, secrecy studies, Donald J. Trump, WikiLeaks

President Donald J. Trump has made a public spectacle of his secrets. He is infamous for the secrets he has kept from the public: Trump's refusal to release his tax records (Shear, Eder, and Cohen 2017) and his hot-mic confession of sexually predatory actions (Fahrenthold 2016) have been the cause of much suspicion and outrage. One might also say that Trump projects an aura of secrecy onto his allies and adversaries. Among his associates, Trump's secret aura is like a cloud of guilt-by-association in which sacrificial scapegoating frees the President from blame. ${ }^{1}$ When 
projecting this aura onto his enemies, Trump often leans upon the strategy of gaslighting, whereby the accused turns the accusation upon the accuser in "a deliberate attempt to deceive someone into questioning their own perception of reality" (Gibson 2017). In that regard, Trump has been most vocal about his opponents' secret agenda to undermine him, the "rigging" of the election, and that former President Obama had unjustly wiretapped his home and business at Trump tower (Clifton 2017). Secrets are, in sum, key to Trump's successful lying, especially when he lies for the apparent purpose of deflecting the public's glare from his media spotlight.

However, secrets are also anathema to President Trump and threaten his authority as executive. In this essay, my objective is to take stock of how one such secret has been figured, rhetorically. This means that I am less interested in the contents of any one secret kept by the administration than with the process by which a series of secrets or leaks unfold as a pattern of expectation and desire. Perhaps counterintuitively, I insist that Trump's secrets not be understood in terms of the specifics he has conjecturally hidden from the public. Rather, the secret consists in the continuous and rhetorical production of public doubt about Trump's ascendancy to and execution of the presidential office. As concerns the pivotal moment described by this essay, it is not that Trump's "I love WikiLeaks" statement 
speculatively marks a hidden secret. Rather, my argument is that the suggestive repetition of this phrase at a remove from the context of its original utterance signifies a gap that cannot be easily resolved, or a secret that is the product of overt contradiction between Trump's statement and its recurrence. Taken in this way, the secret is less an object to be discovered than a process of rhetorical invention, one that sustains public attention by holding out and deferring the secret's revelation.

My central claim is that rhetoric, secrets, and algorithms have been the generative force behind many of Trump's secrets. The identityanonymizing algorithms of the WikiLeaks submission system were a prominent part of the 2016 election due to the steady stream of information Julian Assange published both from and about the Democratic party. Just as crucially, rhetoric and the algorithm share a family resemblance. Anonymous leaks can only be figured as secrets insofar as they are organized by an algorithm-like rhetorical formula. The rhetorical protocols described in this essay is ellipsis, which is an important trope in the rhetorical lexicon because it describes a narrative technique of deflection, interruption, and omission. This trope should be of interest to those with investments in secrecy studies, which addresses "inherently complex" problems of secrecy by secrecy by "creating novel visions and tools to expand understanding of secrecy and its 
charm across intellectual landscapes, genres, and fault-lines" (Maret 2016, 7). In my retelling, ellipsis produces the secret by marking the long silence between an utterance and its repetition as a generative moment of the Trump presidency.

The following sections elaborate on the rhetorical contribution to secrecy studies as well as how rhetorical scholars and cultural critics have conceived of the relationship between rhetoric, algorithms, and secrecy. I then read the elliptical Wikileaks scandal of the 2016 election season. Because the secrets engendered by the "I love WikiLeaks" moment directly rely upon the use of anonymizing algorithms, the fundamentally algorithmic character of ellipsis should highlight for secrecy scholarship stakeholders how rhetoric is, beyond its traditional understanding as persuasive technique or interpretation, also a discursive protocol that orients the public to institutional crises of secrecy. Understanding rhetoric in this way is enabling because it highlights the roles of discourse and its absence in constituting the secret and names precisely the ritual process by which the secret unfolds. It is also enlightening because it illustrates how certain speech-acts can undermine the very aura of secrecy they seek to convey.

\section{Rhetoric and Secrecy Studies}


Broadly speaking, rhetorical scholarship contributes the argument that the production, distribution, and understanding of intelligence information into public depends upon rhetorical persuasive techniques or a rhetorical process of textual interpretation. In this essay, I will take things in a somewhat different direction, arguing with Joshua Gunn that rhetoric constitutes the secret as a psychodynamic relationship.

On the one hand, scholars have argued that secrecy in national intelligence gathering and dissemination is rhetorical because such practices rely on persuasive techniques leading to deception or subterfuge. One example comes from argumentation scholar Gordon Mitchell (2006), who carefully traces the polarization of and rule breaking in cooperativecompetitive debate exercises conducted between the analysts of national intelligence agencies. Drawing upon the work of Stephen Hartnett and Laura Stengrim, Mitchell $(2006,157)$ also draws attention to fringe "Team-B" analyst-groups' technique of stovepiping, which "involves the inappropriate transmission of raw information to intelligence consumers" through "channels that circumvent institutionalized vetting procedures." A separate instance of strategic-rhetorical institutional concealment on the part of major government agencies comes from rhetorical scholars Kristen Hoerl and Erin Ortiz $(2015,591)$, who describe "how the goal of concealing their operations 
structured the FBI's written communication," leading the organization "to strategize methods for hiding the identities of agents as sources of anonymous messages." Even the way that the executive branch organizes their public discourse on national intelligence is deeply rhetorical. Resuscitating the archaic Latin trope occultatio, Donovan Conley and William O. Saas $(2010,330)$ address "the manner by which the Bush administration actively courted the gaps between the American citizenry, the rule of law, and its own 'war on terror."' Whether by way of dissimulation or dissemination, communicating intelligence is rhetorical because ultimately, persuasive technique underwrites these speech-acts.

On the other hand, secrecy in national intelligence is rhetorical because it relies on processes of textual interpretation and a keen awareness of absences and omissions. According to International Relations scholar James Der Derian $(1992,26)$ "a rhetorical approach...is attuned to this fundamental aspect of language: that often, what is said is not what is meant is not what is said." Indeed, the public communication of intelligence is fraught because the intentions of the author are difficult to reconstruct. Instead, the rhetorical approach to intelligence "assigns meaning to the status and capability of the reader," who is more-or-less attuned to the interests that underwrite publicly disseminated intelligence. Hartnett and 
Stengrim $(2006,50)$ concur that "much of what passes for intelligence analysis is an inherently contested process of interpretation - it is not truth telling, not the collection of certainties, but the gathering of clues and hunches, the collection of shards that need careful sifting and cautious reading." The interpretation of intelligence is rhetorical, in other words, because it rests upon a foundation of fragments that must be creatively reassembled in discourse for the consumption of audiences who separately but simultaneously demand appeasement and aggression. ${ }^{2}$ In the words of Cultural Studies scholar Chris Hables Gray $(1997,243)$, the discursive unity of postmodern war is defined by "the metaphors and symbols that structure it, not the direct continuity of weapons, tactics, or strategy between its various manifestations." Rhetoric, in sum, describes how discursive fragments are wielded to construct an interpretive framework for military and wartime policy.

A third way that the public packaging of intelligence information is rhetorical regards the psychodynamics of secrecy. The psychoanalytic term of art "psychodynamics" commonly refers to the way that speech-acts coorient speakers and auditors to a secret as a common object of desire or fascination. In his essay on the decline of Masonic culture in the United States, Joshua Gunn $(2008,246)$ argues that the choice to employ a 
Secrecy and Society, Vol. 1, No. 2 [2018], Art. 2

language of transparency "works to erode the inexhaustible secret upon which the fraternity is based." As Gunn $(2008,253)$ explains, the inexhaustible secret is an "object of public formation" that "cannot be exhausted of meaning or enjoyment; some aspect of that object must remain mysterious and beyond comprehension." The inexhaustible secret places the psychodynamics of rhetoric on display because the choice to employ the rhetorical strategy of transparency makes the secret into "the cause of renewed public interest" while also diminishing its role as "'social capital' that provides Masons a sense of community or 'fellowship.'" (Gunn $2008,246)$ The psychodynamics of rhetoric consist in the way that the discourse enlisted to either guard secrets or put them on display constitutes a clandestine public or alternately, threatens it with unbinding dissolution.

The secrets of Donald J. Trump considered here are similarly rhetorical in that they put the psychodynamics of his presidential rhetoric on public display. As Gunn's account of the Freemasons demonstrates, the secret centered by the psychodynamic relationship is one in which the unbinding effects of rhetoric are as secret to participants as the deep hermeneutics of the inexhaustible secret that they ought to guard. In the present case, the effects of Donald Trump's "I love WikiLeaks" moment are similarly as secret to Donald Trump as the hoard of (personal, financial, etc.) secrets Donald 
Trump may keep. The contribution of this essay to rhetorical scholars goes beyond the idea that rhetorical discourse produces psychodynamics by arguing that psychodynamics are themselves rhetorical. Because the public's co-orientation to such secrets can only be imputed retroactively, assigning a name to any secret's structure of co-orientation is always an active rhetorical process - one that requires taking stock of the way that discourse functions like a algorithm that institutes a pattern among familiar elements.

\section{Rhetoric, Algorithms, and Secrets}

In the Gorgias, Plato defines Rhetoric as a stochastic art to designate it a practice that is "neither scientific nor easily calculable" (London 2001, 572). Today, "stochastic" is less tethered to Rhetoric than to the sciences of chance, probability, and prediction. For the computer scientist, "stochastic" denotes a subset of algorithms that execute complex protocols based on calculations of chance and aggregate massive quantities of data for modelling and prediction. Stochastic does not simply have different meanings that vary per context, audience, or history. The co-naming of Rhetoric and algorithm-writing as "stochastic arts" also suggests that Rhetoric and the algorithm may have more in common than Plato or programmers might imagine. 
Rhetoric is most often defined, vis-à-vis Aristotle, as the faculty of observing in any given case the available means of persuasion: the discursive, presentational, and situational resources available to an orator for moving an audience. Among a certain cadre of rhetorical scholars, mathematics is also understood as foundationally rhetorical, employing or demonstrative of some persuasive strategy. One argument in support of this position is that rhetoric is the strategy of invention mathematicians employ in their discovery and presentation of groundbreaking theory. Dale Cyphert $(1998,88)$ for instance insists that Kurt Gödel's famous uncertainty theorem is also a profound demonstration of a rhetorical paradox in which the act of inventing formal rules "undermines the certainty that such rules are meant to support." Similarly, the simultaneous but separate inventors of calculus, Isaac Newton and Gottfried Wilhelm Leibnitz, employed what G. Mitchell Reyes $(2004,165)$ terms the rhetoric of the infinitesimal, a strategy that made "a new form of mathematics...possible."

Algorithms have also been considered rhetorical for separate, though related reasons. According to Chris Ingraham (2014) algorithms are rhetorical not only because creative mathematical theories undergird them, but also because they engender innocuous everyday persuasion for digital consumers. This is what Ingraham $(2014,63)$ coins "algorithmic rhetoric," 
which describes the imperfection, uncertainty and persuasion engendered by public-facing programming upon mass culture:

[Algorithms] are best understood as rhetorical if we consider that their outcomes are not empirically inevitable, but rather the product of a particular set of parameters designed strategically to lead to a particular kind of result. In other words, algorithms implicitly make a rhetorical argument for what factors matter in order to persuade their "audience" that their resultant outcome is the best, truest, or most important.

Taken at face value, rhetoric denotes a persuasive influence exerted over an audience, and algorithmic rhetoric the selection of the "best" search terms or "truest or most important" input variables. It describes the simultaneously enabling and insidious social consequences of the mathematical procedures that effect persuasion by intuiting choices for end-users.

Rhetoric and algorithms, finally, have the shared property of concealing, revealing, and producing secrets. Cultural critics habitually equate secrets with the contents concealed and revealed by computer algorithms. Gregory Seigworth and Matthew Tiessen $(2012,50)$ claim that algorithms have three secret-oriented functions: to create "pockets" of concealed content, "pools" of intimacy and revelation, and "plasmas" of ever-more-widely dispersed and microscopic surveillance techniques. Algorithms are also understood to be inherently secretive because they are, in Ingraham's $(2014,67)$ words, "hidden automated procedures" that act as 
Secrecy and Society, Vol. 1, No. 2 [2018], Art. 2

the "invisible but driving force behind the technologically mediated aspects of our current human condition." The secret life of algorithms ultimately seems to have dire consequences for healthy public culture. Ted Striphas $(2015,396)$, for instance, warns that "what is at stake in algorithmic culture is the gradual abandonment of culture's publicness." Taste-making algorithms make the creation of culture a private, patent-protected enterprise capable of marginalizing entire populations while "creating ... associations that resemble publics" (McKelvey 2014, 598) as when Amazon.com, unannounced, labeled queer literature as pornography in 2009 (Striphas 2015, 396). As Jodi Dean $(2002,12)$ argues in Publicity's Secret, finally, algorithms generate what counts as secret by holding out "the promise that the answers are out there, that all we have to do is find the evidence and make the links and then we will know."

To the above-cited perspectives on rhetoric, algorithms, and secrecy I would add the observation that rhetoric and the algorithm denote fundamentally similar protocols. Rhetoric is not just the persuasive human output of algorithmic selection-processes; it is also its own specialized process by which the secret, the public's epistemological limit, is figurally constituted. Whereas the algorithmic rhetoric described above denotes levels of persuasion evident in or resulting from computational design, my claim is 
that a rhetorical algorithm describes the procedure by which the secret is added to a system as the symbol of its deficits. Moreover, if rhetoric too often describes the persuasive action of a discernable (i.e. human or computerized) agent, my position is that rhetoric, like the algorithm, operates without such easily identifiable actors and across a dispersed network of signifiers and discourse. From this perspective, individuals do not so much use rhetoric in their discourse as they are used by it, figured by trope as part of a larger, eclipsing narrative. Whereas rhetorical scholars are most often prone to attribute persuasive force to mathematical protocols, my objective is to foreground the isomorphism between rhetoric and algorithm to highlight their shared role in producing the elliptical secret of Donald Trump's "I love WikiLeaks" statement. The "I love WikiLeaks" statement returns us also to the psychodynamics of the secret, in which rhetoric carries effects well beyond the awareness of orator or audience.

\section{Ellipsis and "I Love WikiLeaks"}

According to the Oxford English Dictionary, algorithm originates as a vulgar Western translation of the Arabic name Muhammad ibn Musa alKhwarizmi, the author of On the Calculation with Hindu Numerals. ${ }^{1}$

\footnotetext{
${ }^{1}$ Phonetically "al-kwär'ı̌z-mē," and later transliterated into Latin as Algaurizin and Algoritmi.
} 
Secrecy and Society, Vol. 1, No. 2 [2018], Art. 2

Separated from the name, the term algorithm retains the following signification: "The Arabic system of numbering, [which is to say, a system] characterized by a zero" (OED Online 2017b). The etymology of "algorithm" also marks a series of crucial conceptual discoveries. Prior to the phrase "cypher in algorism" Western number systems simply made do without zero (OED Online 2017a). Even among the Arabian mathematicians who were its discoverers, zero was a foreign symbol, imported from India and added to their existing arithmetic. ${ }^{3}$ To this day, "algorithm" brings the zero into existence as a symbol defined by difference. As George Dyson (2012, 3) writes, "to a digital computer, the only difference that makes a difference is the difference between a zero and a one."

In the rhetorical tradition, the trope that captures the zero's range of functions is ellipsis, which captures the paradox of bringing forth lack, emptiness, or absence with a visible graphic mark. ${ }^{4}$ It is most often represented as three recurring baseline dots (...) that offer readers "a sign of incompletion, suspension, and change of direction" (Brooks 1985, 49). Gérard Genette $(1980,40)$ traces ellipsis back to its Greek root, -lipse, "which refers ... to the fact of leaving out, passing by without any mention." The rhetorical mark of "leaving out" or "passing by" also fulfills an important narrative function: it sutures a story's relevant scenes, omitting intrusive 
extradiegetic noise. Ellipsis, whether a break on the page or a cinematic cut, marks a discontinuity and suspends narrative time (Chatman 1978, 71).

Even if events are later revealed to have occurred in the time elided, ellipsis dismisses these occurrences in the moment as immaterial to the plot's progression and continuity.

Ellipsis has a final function that puts it into zero's company: it furnishes a graphic mark to indicate that a narrative is only partially complete. Ellipsis, in other words, adds the secret to discourse in the form of a signifier of omission, one that is both part of the plot and undermines it coherence. This signifier need not, however, be the traditional graphic mark (...) but any signifier that signals a lack of subtending narrative cohesion. ${ }^{5}$ Joan Copjec (1994) offers an instance of ellipsis when citing Alfred Hitchcock's account of the following scene, omitted from the final cut of North by Northwest:

I wanted to have a long dialogue scene between Cary Grant and one of the factory workers [at a Ford automobile plant] as they walk along the assembly line. They might, for instance, be talking about one of the foremen. Behind them a car is being assembled, piece by piece. Finally, the car they've seen being put together from a single nut and bolt is complete, with gas and oil, and all ready to drive off the line. The two men look at each other and say, "Isn't it wonderful!" Then they open the door to the car and out drops a corpse. (Truffaut 1983, 257) 
Secrecy and Society, Vol. 1, No. 2 [2018], Art. 2

The question, as Copjec $(1994,170)$ elaborates, is "where has the body come from?" By inviting this question, the body emerges as the unmistakable signifier for an omission from the greater plot. Like the algorithm's zero, this ellipsis adds a signifier to discourse to mark the knowledge-gap missing from it.

The 2016 presidential election generated numerous elliptical signifiers. Donald J. Trump's accusations of wiretapping, for instance, are elliptical secrets because of the way that "wiretapping" insistently resurfaced despite evidence to the contrary. After accusing President Obama of having wiretapped Trump Tower in conjunction with the British government, former Obama officials James Comey and Mike Rogers testified in March 2017 that no such recordings had ever been made (Lapowsky 2017). Trump's insistence on the wiretapping claim in the face of contradicting evidence led the National Review to claim that these allegations were a "self-inflicted wound" that dealt a serious blow to the United States' relationship with British government officials (Geraghty 2017). Wiretapping is elliptical, in this case, because it functions as a signifier of secret omission: Trump's refusal to let go of the wiretapping signifier gestured to an unstated surplus of motivation for keeping the topic alive. 
A more involved example of ellipsis is Donald J. Trump's "I love WikiLeaks" moment, which capitalized on anonymizing algorithms developed by WikiLeaks affiliates Julian Assange and Jacob Appelbaum. The ellipsis of Trump's declaration, "I love WikiLeaks," was initiated on the campaign trail in early October 2016: "It's amazing how nothing is secret today when you talk about the Internet" (Hensch 2016). Trump was, at the time, referring to one of many damaging leaks to Democratic presidential nominee Hillary Clinton. That June, WikiLeaks had disclosed information gathered by anonymous hackers about the Democratic National Committee (DNC), showing that "party officials [conspired] to sabotage the campaign of Senator Bernie Sanders of Vermont" (Martin and Rappeport 2016). That disclosure, timed to coincide with the imminent Democratic National Convention in Philadelphia, resulted in the resignation of DNC chairman Debbie Wasserman-Schultz on its first day. Soon after, the pseudonymous hacker "Guccifer 2.0" claimed responsibility for the leak. News outlets like The New York Times (Sanger and Perlroth 2016) reported that the hack was more likely perpetrated by hacker groups "Cozy Bear" and "Fancy Bear" independently operated by the Russian military intelligence service. ${ }^{6}$ The first ellipsis of "I love WikiLeaks" was thus an omission of responsibility for these leaks. Despite accreted evidence that the Kremlin was responsible, 
candidate Trump remained stalwart by refusing to attribute blame, shrugging off official reports and casting aspersions upon President Obama's national security experts. According to the soon-to-be president, "I don't think anybody knows it was Russia that broke into the DNC. I mean, it could be Russia, but it could also be China. It could also be lots of other people. It also could be somebody sitting on their bed that weighs 400 pounds, okay?" (Priest and Hamburger 2016). Candidate Trump was more than willing to ignore the 400-pound elephant in the room. By his reasoning, anyone could have leaked the documents, and there was therefore no reason for the United States to accuse Russia.

Trump's elliptical omission of Russia vis-à-vis his endorsement of WikiLeaks capitalized on uncertainty generated by the computer algorithms used to leak DNC data, forming part of what is more generally known as "the attribution problem." Among hackers and criminologists, the attribution problem describes the difficulty of naming a perpetrator of a cyberattack, owing to the ways hackers may obscure their identity or lay false trails (Newman, 2016). The problem, when wielded as political argument, also injects uncertainty into leaking controversies by making the detection of cyber-criminals appear impossible. When Trump stated that he loved WikiLeaks, he named an infatuation with uncertainty - specifically, with the 
uncertainty of knowing who committed the cybercrimes that benefitted his campaign. He also celebrated the anonymizing mechanism that made this uncertainty possible. ${ }^{7}$ WikiLeaks had years before devised a solution to the attribution problem by anonymizing their submissions through Tor (an acronym for The Onion Router), a software that would encrypt whistleblower identities beyond recognition. As The New York Times reported in an interview with WikiLeaks affiliate and Tor developer Jacob Appelbaum:

A Tor transmission these days might start in Addis Ababa, hop to Dallas, then to Stockholm and finally Johannesburg...The only thing the Johannesburg recipient can discover is that the data came from Tor, and Tor has successfully identified itself with no person or group, only with ideological incoherence... With Tor, you "only reveal the information that you type," Appelbaum says, "As opposed to all the other information that comes along when you use your computer." (Heffernan 2010)

In Assange's words, "Tor's importance to WikiLeaks cannot be overstated" (Rich 2010). Tor effectively provided WikiLeaks with plausible deniability about the whistleblower identities. It did not matter whether it was Russia or an independent hacker who submitted State secrets to WikiLeaks; Assange could publish erstwhile claiming never to have known his source. So too with Trump. During Trump's campaign, WikiLeaks was an invaluable asset because it afforded him plausible deniability about the perpetrator of the DNC leaks. Absent a digital record of the leak's origin, there was by Trump's 
Secrecy and Society, Vol. 1, No. 2 [2018], Art. 2

logic no way to legitimately draw connections between Russia, WikiLeaks, and ultimately, himself. ${ }^{8}$

Of course, algorithm-granted protections of anonymity returned to haunt Donald J. Trump's early days as President. On January 10, 2017, Buzzfeed News released a British Intelligence Dossier on President Trump that included "specific, unverified, and potentially unverifiable allegations of contact between Trump aides and Russian operatives, and graphic claims of sexual acts documented by the Russians" (Bensinger, Elder, and Schoofs). Although the identity of the dossier's author, former MI-6 agent Christopher Steele, was publicized soon after the disclosure, the dossier was itself leaked after being presented to Obama, Trump, and top-level intelligence officers before circulating among reporters (Blum 2017). Although many were suspicious of the information, former NSA lawyer Susan Hennessy noted that "both Obama and Trump were briefed on the report in a meeting with the heads of the NSA, CIA, FBI and Office of the Director of National Intelligence," signaling that U.S. Intelligence agencies at least consider its contents important, if not altogether true" (Greenberg 2017a). The day after the leak, President Trump announced his intention to present a "major report on hacking defense," claiming that the United States was simply too vulnerable to cyber-attacks and required "as a deterrent against attacks on 
our critical resources...the unquestioned capacity to launch crippling cyberattacks" (Newman 2017a). The March 11 statement was a major about-face for the administration about leaks. Even as he refused to acknowledge Russia's role in the 2016 election vis-à-vis WikiLeaks, President Trump declared leaks to be criminal acts and announced his intent to wage war on the cyber-crimes that had left America - and more recently, himself - exposed. In the following month, news outlets reported rising use of endto-end text encryption apps and, relatedly, leaks from Washington insiders. In March, House Select Intelligence Committee hearings about Russian tampering with the 2016 election established that leaks were less of a threat to the Republic than domestically-based leakers. Avoiding the topic of Russia almost entirely, the convened Committee instead "excoriated whoever brought those allegations to the public in the first place" and made glaring accusations against top level officials like Director of Intelligence James Clapper (Barrett 2017). Ultimately, the hearings resolved little about the role of Russian hackers in the 2016 election because they returned to the frustrating (and by now familiar) problem of attribution: whodunit?

"I love WikiLeaks" and its by-now forgotten celebration of anonymity returned as a second ellipsis following the March 2017 "Vault 7" leak, consisting of 8,761 documents and a portion of "the CIA's hacking arsenal" 
Secrecy and Society, Vol. 1, No. 2 [2018], Art. 2

(Newman 2017b). Vault 7 contained Apple and Android smartphones hacking vulnerabilities that had been left unreported, implying "that the CIA - along with other intelligence agencies - has long allowed Americans to remain vulnerable to these attacks" (Greenberg 2017a). The leak similarly led former spy and convicted leaker John Kirakou to describe the Vault 7 whistleblower as having acted in the public interest by disclosing "a danger to public health and safety" (Ellis 2017). Whatever public interest it may have served, President Trump and Attorney General Jeff Sessions responded to the leak by telegraphing plans to bring criminal charges against Julian Assange (Greenberg 2017b). In response, a jilted Assange tweeted Trump a video of his October "I love WikiLeaks" endorsement (Seipel 2017). As Trump had portentously declared in October, "It's amazing how nothing is secret today when you talk about the Internet" (Hensch 2016).

The return of the "I love WikiLeaks" statement enunciated the senseless contradiction between Trump's earlier statement that Russian hackers were totally blameless for tampering with the election while Washington leakers were total criminals. It signaled an abrupt about-face of the administration not only on Julian Assange, but on the virtues of leaking information more generally. In the words of Steven Aftergood of the Federation of American Scientists' Project on Government Secrecy, Trump's 
campaign to purge leakers from D.C. was "a broader objection not to any individual leak so much as to the fact of independent reporting that is at odds with the White House narrative" (Watkins and Dawsey 2017). Most of all, the statement made Trump's campaign connections to Russian officials more prominent. In early July, Donald Trump Jr. published emails via Twitter between himself and a Russian government attorney regarding promises of "very high level and sensitive information" (Diamond 2017). According to Julian Assange, once again in the good graces of the Trump family, who had advised Trump Jr. to leak the information anonymously through WikiLeaks, the public Twitter post made the secret communications "easier to submit as evidence" in Robert Mueller's ongoing FBI investigation of White House (Smith 2017). Indeed, the whole affair highlighted the open hypocrisy between Trump's war on leakers and his open channel to Julian Assange, between his desire for leaked information and his moratorium on transparency in the White House. It signaled beyond all doubt that even if the leaks Trump sought to prevent were never to be known, the unwitting and repeated revelation of his own shrouded connections demonstrated a surplus of desire to protect what was hidden, and implied a surfeit of secrets yet to be found. 
Ultimately, the elliptical trajectory of "I love WikiLeaks" sutures a story of secrecy told by and about the Trump administration. Ellipsis lies in the fact that "I love WikiLeaks" is a signifier of omission - referring to Trump's omission of Russian responsibility in the first instance, and to the omission of his own, earlier statements in the second. In that sense "I love WikiLeaks" consistently returns as the signifier for the secret. Whereas "I love WikiLeaks" initially celebrated attributive uncertainty, Assange's tweet turned the problem of perpetration back on the President by making his amorous speech into the conspicuous signifier of his administration's narrative discontinuities. Like the zero, "I love WikiLeaks" is a signifier of omission added after-the-fact into political discourse to index its missing secret.

\section{The Secret is Rhetorical}

This essay's core contribution is a rhetorical theory of the secret bound to the trope of ellipsis, offered as a rhetorical-algorithmic formula for the secret produced by Donald Trump's "I love WikiLeaks" moment. Ellipsis, I have argued, describes an algorithm-like pattern of omission that constitutes the secret as an absence that returns when unspeakable signifiers are spoken. Ellipsis, moreover, is altogether as significant for constituting the 
secret as the anonymizing algorithms that underwrote the "I love WikiLeaks" scandal. As a psychodynamic function, finally, the trope of ellipsis adds a secret to discourse by materializing a gap, omission, or elision between the speech-act and its repetition. It is this secret surplus added by ellipsis that often operates outside the awareness and against the interests of its originator.

Early in this essay, I also suggested that a rhetorical approach responds to the call of secrecy studies to "carve out new territory through the shaping of theory and definitions" by way of an alternative telling of history (Maret 2015, xvii). A rhetorical approach characteristically avoids the lure of the secret's content, or the temptation to dive into the specifics of what Donald Trump has conjecturally hidden from the public. Instead, by examining the way that utterances like "I love WikiLeaks" are unmade by their repetition, the rhetorical approach to the secret illustrates how the secret is both public and spectacular. Furthermore, a crucial function of rhetorical analysis is to offer up a name for what has been missing from the larger scene, thereby giving the epistemological barrier erected by the secret a positive presence in public discourse.

To conclude, I will offer final illustration of this essay's core argument regarding the discovery of Trump's secrets. The temptation to discover some 
hidden content in yet another document, source, or signifier is put on display with the previously cited Christopher Steele report, published on Buzzfeed in early January 2017. The report offered an account of two separate Russian operations: the first, an effort "to influence Mr. Trump" using "an array of familiar tactics: the gathering of 'kompromat,' compromising material such as alleged tapes of Mr. Trump with prostitutes in a Moscow hotel, and proposals for business deals attractive to Trump" (Shane, Confessore, and Rosenberg 2017). The second "described the hacking of the Democratic National Committee and Mrs. Clinton's campaign chairman, John D. Podesta" (Shane, Confessore, and Rosenberg 2017). The report did not just connect loose threads between Trump, Russia, and WikiLeaked documents; it also instituted a profound amount of hand-wringing over the verifiability of Steele's intelligence. According to Forbes "free-market perspective" contributor Paul R. Gregory (2017) the details of the report were circumspect, rang more of gossip than truth, and would prove impossible to verify. Vanity Fair journalist Howard Blum (2017) answered the question "how good were [Steele's] sources?" by highlighting their impressive credentials: "Source A was 'a senior Russian Foreign Ministry figure'," "Source B was 'a former top level intelligence officer still active in the Kremlin'," and Source E, who had "admitted there was a well-developed 
conspiracy of cooperation between [the Trump campaign] and the Russian leadership," was "'an ethnic Russian' and 'close associate of U.S. presidential candidate Donald Trump." In September 2017, Julian Assange took to Twitter to settle the issue once and for all, arguing that in the FBI's ongoing investigation of Russian connections to the Trump campaign, Robert Mueller had not once "bothered to contact WikiLeaks or me [Assange], in any manner, ever" (Johnstone 2017). The argument was that if Mueller were not supporting an ideological campaign against Donald Trump, he would have at least attempted to contact Assange. According to WikiLeaks' proponents, the Steele report must be conclusively false because Assange claimed to know something about the substance of the leak that no one else could possibly know: that the DNC leakers were not Russian (Mai-Duc 2017). Ultimately, at stake in all this handwringing over the Steele report was the verifiability of the dossier and its contents. If the analysis of rhetoric were concerned only with uncovering this content, it could to look no further.

Instead of taking Julian Assange at his word about the contents of the Steel dossier, a more careful rhetorical analysis would insistently scrutinize what Assange failed to repeat in threatening to out the true sources of the DNC leak: any mention of his submission-anonymizing algorithm. The ellipsis by which Assange omits his own anonymizing algorithm highlights 
the central argument of this essay: When we read rhetorically, we refuse being taken in by the substance of any given secret (like the Steele dossier), but instead understand such revelations as one part in a pattern of expectation and desire. Assange's admission of knowing sidesteps entirely the anonymizing algorithm should have prevented even him from knowing the identity of the DNC leaker. By asserting that he knew the identity of the leakers, Assange forwent the protections of anonymity previously guaranteed by WikiLeaks and Tor and instead claimed direct knowledge of the individual(s) behind Trump's "I love WikiLeaks" declaration. This act, alongside Assange's hot-and-cold relationship with Donald Trump and his family, enables us to ask questions not only about the veracity of Assange's (or Trump's) speech, but also about the recurrent habits of speaking that are generative of their shared secret. If Assange can claim to know the identity of a leaker in one instance but not another, is it because he has circumvented the whistleblower protection he advertises, or because of an interest in seeing the connection between the DNC leak and Russia disappear? Alternately, if Assange knows the identity of the DNC leaker with protections of anonymity intact, then why would they have informed Assange of their identity? Most of all, if Assange knows the identity of the leaker(s), why would he offer now to out them? 
Ultimately, the secret is rhetorical because, like the algorithm's zero, it is actively and retroactively produced as a mark of omission. Whereas rhetoric is often equated with deception (and secrets with concealed content), I have sought to bind these terms to the algorithms that underwrote and over-coded the secrets of the 2016 election. Moreover, rhetoric is imbued with its own algorithmic qualities. It is not only the case that algorithms provide transparent access to missing secrets or that they offer an expedient route to discovering them. Rather, the algorithm and rhetoric both add a new element (zero and the secret) to their existing systems to indicate what is lacking from them. In the words of Roberto Simanowski $(2016,10)$, "the algorithm is the psychoanalyst of the twentyfirst century, delineating patterns of behavior that had previously remained hidden." If that is the case, it is because the algorithm is tethered to established rhetorical tropes like ellipsis that bring the secret forth as conspicuous absences and underreported history. 


\section{References}

Badiou, Alain. 2009. Logics of worlds: Being and event II. Translated by Alberto Toscano. Brooklyn: Verso.

Ball, James. 2011. All the encryption in the world wouldn't have kept Bradley Manning safe. The Guardian, July 16. https://www.theguardian.com/commentisfree/2011/jul/16/bradleymanning-wikileaks-security

Barrett, Brian. 2017. Russia? Nah. The house GOP goes after leakers instead. WIRED, March 20. https://www.wired.com/2017/03/heyhouse-gop-leakers-arent-enemy/

Bensinger, Ken, Miriam Elder, and Mark Schoofs. 2017. These reports allege Trump has deep ties to Russia. BuzzFeed News, January 10. https://www.buzzfeed.com/kenbensinger/these-reports-allege-trumphas-deep-ties-to-russia.

Blum, Howard. 2017. How ex-spy Christopher Steele compiled his explosive Trump-Russia dossier. Vanity Fair, April. http://www.vanityfair.com/news/2017/03/how-the-explosive-russiandossier-was-compiled-christopher-steele

Brooks, Peter. 1985. Reading for the plot: Design and intention in narrative. New York: Vintage Books.

Buchanan, Larry, Alicia Parlapiano, and Karen Yourish. 2017. Here are the top officials in the Trump White House who have left. The New York Times, August 26. https://www.nytimes.com/interactive/2017/08/18/us/politics/whitehouse-staff-fired-resigned.html 
Bump, Phillip. 2017. What Jeff Sessions said about Russia, and when. The Washington Post, March 2.

https://www.washingtonpost.com/news/politics/wp/2017/03/02/whatjeff-sessions-said-about-russia-and-when/

Chatman, Seymour. 1978. Story and discourse: Narrative structure in fiction and film. Ithaca: Cornell University Press.

Clinton, Hillary. 2010. Clinton condemns leak as "attack on international community." CNN.com, November 30. http://www.cnn.com/2010/US/11/29/wikileaks/index.html

Clifton, Denise. 2017. How Trump and his allies have run with Russian propaganda. Mother Jones, June 5. http://www. motherjones.com/politics/2017/06/russian-activemeasures-trump-propaganda-conspiracy-theories/

Conley, Donovan, and William O. Saas. 2010. Occultatio: The Bush administration's rhetorical war. Western Journal of Communication 74: 329-350.

Copjec, Joan. 1994. Read my desire: Lacan against the historicists. Cambridge: The MIT Press.

Cyphert, Dale. 1998. Strategic use of the unsayable: Paradox as argument in Gödel's theorem. Quarterly Journal of Speech 84: 80-93.

Dean, Jodi. 2002. Publicity's secret: How technoculture capitalizes on democracy. Ithaca: Cornell University Press. 
Der Derian, James. 1992. Antidiplomacy: Spies, terror, speed, and war. Cambridge: Blackwell Publishing.

Derrida, Jacques. 1998. Of grammatology. Baltimore: Johns Hopkins University Press.

Diamond, Jeremy. 2017. Donald Trump Jr. releases email chain on his Russian meeting. CNN Politics, July 11. http://www.cnn.com/2017/07/11/politics/trump-jr-russia-lawyeremails/index.html

Dyson, George. 2012. Turing's cathedral: The origins of the digital universe. New York: Random House.

Ellis, Emma Grey. 2017. Convicted leaker John Kiriakou's got some opinions about WikiLeaks and Trump. WIRED, March 14. https://www.wired.com/2017/03/cia-whistleblower-talks-vault-7wikileaks-president-trump/

Entous, Adam, Ellen Nakashima, and Greg Miller. 2017. Sessions met with Russian envoy twice last year, encounters he later did not disclose. The Washington Post, March 1. https://www.washingtonpost.com/world/national-security/sessionsspoke-twice-with-russian-ambassador-during-trumps-presidentialcampaign-justice-officials-say/2017/03/01/77205eda-feac-11e6-99b49e613afeb09fstory.html

Fahrenthold, David A. 2016. Trump recorded having extremely lewd conversation about women in 2005. The Washington Post, October 8. https://www.washingtonpost.com/politics/trump-recorded-havingextremely-lewd-conversation-about-women-in2005/2016/10/07/3b9ce776-8cb4-11e6-bf8a-3d26847eeed4 story.html 
Genette, Gerard. 1983. Narrative discourse: An essay in method. Translated by Jane E. Lewin. Ithaca: Cornell University Press.

Geraghty, Jim. 2017. Trump's wiretap allegation was a self-inflicted wound. National Review, March 20. http://www.nationalreview.com/article/445929/donald-trump-obamawiretap-allegation-self-inflicted-political-wound

Gibson, Caitlin. 2017. What we talk about when we talk about Donald Trump and "gaslighting." The Washington Post, January 27. https://www.washingtonpost.com/lifestyle/style/what-we-talk-aboutwhen-we-talk-about-donald-trump-andgaslighting/2017/01/27/b02e6de4-e330-11e6-ba1163c4b4fb5a63 story.html

Glaser, April. 2016. Here's what we know about Russia and the DNC hack. WIRED, July 27. https://www.wired.com/2016/07/heres-know-russiadnc-hack/

Gray, Chris Hables. 1997. Postmodern war: The new politics of conflict. New York: Guilford Press.

Greenberg, Andy. 2017a. How the CIA's hacking hoard makes everyone less secure. WIRED, March 8. https://www.wired.com/2017/03/ciashacking-hoard-makes-everyone-less-secure/

. 2017b. The US charging Julian Assange could put press freedom on trial. WIRED, April 20. https://www.wired.com/2017/04/us-chargingjulian-assange-put-press-freedom-trial/

Gregory, Paul Roderick. 2017. The Trump dossier is fake - and here are the reasons why. Forbes, January 13. 
Secrecy and Society, Vol. 1, No. 2 [2018], Art. 2

https://www.forbes.com/sites/paulroderickgregory/2017/01/13/thetrump-dossier-is-false-news-and-heres-why/\#f6716be68674

Gunn, Joshua. 2008. Death by publicity: U.S. freemasonry and the public drama of secrecy. Rhetoric \& Public Affairs 11: 243-278.

Hansen, Evan. 2011. Manning-Lamo chat logs revealed. WIRED, July 13. https://www.wired.com/2011/07/manning-lamo-logs/

Hartnett, Stephen, and Laura Stengrim. 2006. Globalization and empire: The U.S. invasion of Iraq, free markets, and the twilight of democracy. Tuscaloosa: University of Alabama Press.

Hartnett, Stephen. 2011. Google and the "twisted cyber-spy" affair: USChinese communication in an age of globalization. Quarterly Journal of Speech 97: 411-434.

Heffernan, Virginia. 2010. Granting anonymity. The New York Times, December 17. http://www.nytimes.com/2010/12/19/magazine/19FOBMedium-t.html

Hensch, Mark. 2016. Trump: "I love WikiLeaks." The Hill, October 10. http://thehill.com/blogs/ballot-box/presidential-races/300327-trump-ilove-wikileaks

Higgins, Andrew. 2017. Maybe private Russian hackers meddled in election, Putin says. The New York Times, June 1. https://www.nytimes.com/2017/06/01/world/europe/vladimir-putindonald-trump-hacking.html

Hoerl, Kristen, and Erin Ortiz. 2015. Organizational secrecy and the FBI's COINTELPRO black nationalist hate groups program, 1967-1971. Management Communication Quarterly 24: 590-615. 
Ingraham, Chris. 2014. Algorithmic rhetoric. In Digital Rhetoric and Global Literacies: Communication Modes and Digital Practices in the Networked World. Ed. Gustav Verhulsdonck and Marohang Limbu, 62-79. Hershey: Information Science Reference IGI Global.

Jay, Martin. 1993. Downcast eyes: The denigration of vision in twentiethcentury French thought. Berkeley: University of California Press.

Johnstone, Caitlin. 2017. The entire Russian hacking narrative is invalidated in this single Assange tweet. Medium, September 20. https://medium.com/@caityjohnstone/the-entire-russian-hackingnarrative-is-invalidated-in-this-single-assange-tweet-5f36ad25e0f9

Khatchadourian, Raffi. 2011. Manning, Assange, and the Espionage Act. The New Yorker, May 20. http://www.newyorker.com/news/newsdesk/manning-assange-and-the-espionage-act

Lacan, Jacques. 1998. The seminar of Jacques Lacan book XI: The four fundamental concepts of psychoanalysis. Edited by Jacques-Alain Miller. Translated by Alan Sheridan. New York: W. W. Norton \& Company.

Lapowsky, Issie. 2017. Not even the FBI can get Trump to drop his wiretap claims. WIRED, March 20. https://www.wired.com/2017/03/not-even-fbi-can-get-trump-dropwiretap-claims/

Leigh, David and Luke Harding. 2011. WikiLeaks: Inside Julian Assange's war on secrecy. Great Britain: The Guardian.

Leonhardt, David, and Stuart A. Thompson. 2017. Trump's lies. The New York Times, June 23. 
Secrecy and Society, Vol. 1, No. 2 [2018], Art. 2

https://www.nytimes.com/interactive/2017/06/23/opinion/trumps$\underline{\text { lies.html }}$

London, Alex John. 2001. Moral knowledge and the acquisition of virtue in Aristotle's "Nicomachean" and "Eudemian ethics." The Review of Metaphysics 54: 553-83.

Lundberg, Christian. 2012. Lacan in public: Psychoanalysis and the science of rhetoric. Tuscaloosa: University of Alabama Press.

Mai-Duc, Christine. 2017. Rep. Dana Rohrbacker meets with WikiLeaks founder Julian Assange, plans to tell Trump what he heard. Los Angeles Times, August 16. http://www.latimes.com/politics/essential/la-pol-caessential-politics-updates-rep-dana-rohrabacher-met-with-1502940957htmlstory.html

Maret, Susan. 2011. Introduction: Government secrecy. In Government Secrecy, Research in Social Problems and Public Policy, 19, edited by Susan Maret, xi-xxx. Bingley, United Kingdom: Emerald Group Publishing Limited.

. 2016. The charm of secrecy: Secrecy and society as secrecy studies. Secrecy and Society 1: 1-28.

http://scholarworks.sjsu.edu/secrecyandsociety/vol1/iss1/1/

Martin, Jonathan, and Alan Rappeport. 2016. Debbie Wasserman Shultz to resign D.N.C. post. The New York Times, July 22. https://www.nytimes.com/2016/07/25/us/politics/debbie-wassermanschultz-dnc-wikileaks-emails.html

McKelvey, Fenwick. 2014. Algorithmic media need democratic methods: Why publics matter. Canadian Journal of Communication 39: 597-613. 
Miller, Jacques-Alain. 1977. Suture (elements of the logic of the signifier). Translated by Jacqueline Rose. Screen 18: 24-34.

Mitchell, Gordon R. 2006. Team B intelligence coups. Quarterly Journal of Speech 92: 144-173.

Newman, Lily Hay. 2016. Hacker lexicon: What is the attribution problem? WIRED, December 24. https://www.wired.com/2016/12/hacker-lexiconattribution-problem/

. 2017a. Encryption apps help White House staffers leak - and maybe break the law. WIRED, February 15.

https://www.wired.com/2017/02/white-house-encryption-confide-app/

. 2017b. WikiLeaks just dumped a mega-trove of CIA hacking secrets. WIRED, March 7. https://www.wired.com/2017/03/wikileaks-cia-hacksdump/

OED Online. 2017a. Algorism. Oxford University Press. . 2017b. Algorithm. Oxford University Press.

Priest, Dana, and Tom Hamburger. 2016. Trump refusal to accept government assessments on Russian hacks dismays former officials. The Washington Post, October 14. https://www.washingtonpost.com/politics/trump-refusal-to-acceptgovernment-assessments-on-russian-hacks-dismays-formerofficials/2016/10/14/6d1c7f60-8fc4-11e6-9c520b10449e33c4 story.html 
Reyes, G. Mitchell. 2004. The rhetoric in mathematics: Newton, Leibniz, the calculus, and the rhetorical force of the infinitesimal. Quarterly Journal of Speech 90: 163-188.

Rich, Nathaniel. 2010. The American WikiLeaks hacker. Rolling Stone, December 1. http://www.rollingstone.com/culture/news/meet-theamerican-hacker-behind-wikileaks

Sanger, David E. and Nicole Perlroth. 2016. As Democrats gather, a Russian subplot raises intrigue. The New York Times, July 24. https://www.nytimes.com/2016/07/25/us/politics/donald-trump-russiaemails.html

Seife, Charles. 2000. Zero: The biography of a dangerous idea. New York: Penguin Books.

Seigworth, Gregory J., and Matthew Tiessen. 2012. Mobile affects, open secrets, and global illiquidiy: Pockets, pools, and plasma. Theory, Culture \& Society 29: 47-77.

Seipel, Brooke. 2017. WikiLeaks reminds Trump of time he said "I love WikiLeaks." The Hill, April 22. http://thehill.com/blogs/blog-briefingroom/news/330052-wikileaks-reminds-trump-of-time-he-said-i-lovewikileaks

Shane, Scott, Nicholas Confessore, and Matthew Rosenberg. 2017. How a sensational, unverified dossier became a crisis for Donald Trump. The New York Times, January 11.

https://www.nytimes.com/2017/01/11/us/politics/donald-trump-russiaintelligence.html? $r=0$

Shear, Michael D., Steve Eder, and Patricia Cohen. 2017. Donald Trump's taxes: What we know and don't know. The New York Times, March 15. 
https://www.nytimes.com/interactive/2016/us/politics/donald-trumptaxes-explained.html

Simanowski, Roberto. 2016. Data love: The seduction and betrayal of digital technologies. New York: Columbia University Press.

Smith, David. 2017. Julian Assange: I urged Trump Jr to public Russia emails via WikiLeaks. The Guardian, July 11. https://www.theguardian.com/media/2017/jul/11/julian-assangedonald-trump-jr-wikileaks

Striphas, Ted. 2015. Algorithmic culture. European Journal of Cultural Studies 18: 395-412.

Truffaut, Francois. 1983. Hitchcock/Truffaut. New York: Simon \& Schuster Paperbacks.

Watson, Ali, and Josh Dawsey. 2017. Trump's leaks crackdown sends chills through national security world. POLITICO, July 7. http://www.politico.com/story/2017/07/07/trumps-leak-vendettasends-chills-240274

Wines, Michael. 2017. Rebuked twice by Supreme Court, North Carolina Republicans are unabashed. The New York Times, May 27. https://www. nytimes.com/2017/05/27/us/north-carolina-republicansgovernor-gerrymander.html 
1 The ranks of the scapegoats covered by the range of events in this essay include campaign adviser Paul Manafort, former economic consultant Carter Page, and former Trump nominee for Secretary of State, Gen. Michael Flynn. At the time of this writing, the list could be expanded to include Press Secretaries Sean Spicer and Anthony Scaramucci, White House advisers Steve Bannon and Sebastian Gorka, FBI Director Jim Comey, Chief of Staff Reince Priebus, Deputy Chief of Staff Katie Walsh, and Health and Human Services Secretary Tom Price (Buchanan, Parlapiano, Yourish 2017).

2 The notion of simultaneous appeasement and aggression is especially pertinent for Stephen Hartnett $(2011,414)$, who specifically wishes for his readers to bear witness to what he terms "traumatic nationalism," or "the production of a dual strategy, where hostile rhetoric is deployed for populist political purposes at home, in both the US and China, while the interests of realpolitik drive a more measured rhetoric at the highest levels of government."

3 In the words of historian of mathematics Charles Seife $(2000,18)$, "You don't have to have a number to express the lack of something, and it didn't occur to anybody to assign a symbol to the absence of objects." Zero was a transformative import to the Arabic system of number. Zero comes from sunya, Sankskrit for 'void', which in Arabic became sifr, the term for 'empty' (Striphas 2015, 404). Sifr, the zero, also constituted a radical mathematical advancement, granting early mathematicians the ability to write fractions as decimals, to convert along base ten (Seife 2000,18).

4 The operation of adding a graphic mark that symbolizes the limit or ontological lack (lack-in-being) is also what some psychoanalytic scholars have termed the logic of suture or subtraction. The former refers to "the general relation of lack to the structure - of which it is an element, inasmuch as it implies the position of a taking-the-place-of" (Miller 1977, 39). The latter is "an ontology in which evental excess summons lack" (Badiou 2009, 548).

5 Rhetorical and psychoanalytic scholar Christian Lundberg $(2012,3)$ might call the lack of subtending narrative cohesion described in this essay as "feigned unicity between signs, representations, and their referents," which "imagines a unified social field, despite the subject's experience of a fragmented social world." Feigned unicity and the lack of subtending narrative cohesion refer to distinct aspects of a similar problem. Whereas feigned unicity "purchases the subject an ability to act as if words and representations effortlessly stand in for their reference," a lack of subtending narrative cohesion indexes a signifier which persistently undermines the fantasy of its union with a referent.

6 According to evidence accumulated by King's College professor Thomas Rid, there were numerous telltale signs of Russian interference: "[An] identical command-and-control address hardcoded into the DNC malware ... was also found on malware used to hack the German Parliament in 2015. According to German security officials, the malware originated from Russian military intelligence. An identical SSL certificate was also found in both breaches. The evidence mounts from there. Traces of metadata in the document dump reveal various indications that they were translated into Cyrillic. Furthermore, while Guccifer 2.0 claimed to be from Romania, he was unable to chat with Motherboard journalists in coherent Romanian. Besides which, this sort of hacking wouldn't exactly be outside of Russian norms" (Glaser 2016). 
7 In its earliest, most idealistic days, WikiLeaks had intended to employ a wiki-website format, meaning that anonymous informants would be able to edit disclosures at will (Leigh and Harding 2011, 52). In theory, the site would have accepted any whistleblower's anonymous submissions, which could then be authenticated by a transnational audience of "citizen-journalists." But this idealistic vision was quickly dismissed in favor of Tor.

8 It should be noted that this was the also case with Chelsea Manning during the disclosure of the Iraq and Afghanistan War Logs, during which time both Assange and Manning denied having explicitly disclosed each other's identity. As Assange explained in a 2010 interview with George Stephanopoulos, "I had never heard of the name Bradley Manning before it was published in the press. WikiLeaks's technology [was] designed from the very beginning to make sure that we never know the identities or names of people submitting us material. That is, in the end, the only way the sources can be guaranteed that they remain anonymous, as far as we are concerned" (Khatchadourian 2011). Similarly, following accusations from then-Secretary of State Hillary Clinton that Assange's 2010 disclosures "puts people's lives in danger, threatens our national security and undermines our efforts to work with other countries to solve shared problems," Assange responded by claiming that such damages could not be proven: "As far as we are aware and as far as anyone has ever alleged in any credible manner whatsoever, no single individual has ever come to harm as a result of anything that we have ever published" (Clinton 2010). Manning's identity as the perpetrator of these leaks was ultimately discovered by Adrian Lamo, a hacker-turned-FBI informant, who secured a confession during a series of widely-published chat logs (Hansen 2011). It should also be noted that the chat-logs undermine Assange's claim that there was no direct communication between himself and Manning; even if Tor protected whistleblower identities, Assange is alleged to have known at least some personal information about his star 2010 source (Ball 2011). 